\begin{tabular}{cc} 
ACADEMIA ROMÂNĂ & Rev. Roum. Chim., \\
Ro21, 66(1), 59-63 \\
Revue Roumaine de Chimie & DOI: 10.33224/rrch.2021.66.1.06 \\
http://web.icf.ro/rrch/ & \\
\hline
\end{tabular}

Dedicated to Professor Mihaela Hillebrand, on the occasion of her $80^{\text {th }}$ anniversary

\title{
EXCIPLEX FORMATION \\ IN THE PHENOXATHIIN-THIOXANTHONE SYSTEM
}

\author{
Cristina TABLET ${ }^{\mathrm{a}}$ and Sorana IONESCU $\mathrm{U}^{\mathrm{b}, *}$ \\ ${ }^{a}$ Faculty of Pharmacy, Titu Maiorescu University, Gh. Sincai Bd. 16, 040317 Bucharest, Roumania \\ ${ }^{\mathrm{b}}$ Department of Physical Chemistry, University of Bucharest, Bd. Regina Elisabeta 4-12, 030018 Bucharest, Roumania
}

Received October 25, 2020

Amines and other nitrogen-containing compounds, due to their electron donor character, can form excited state emissive complexes in systems that comprise an electron acceptor. Sulphur-containing heteroaromatic compounds such as phenoxathiin are also well-known for their electron donor character. Starting from these two considerations, we aimed at finding exciplexes in which the electron donor contains sulphur. We studied several D-A pairs in solvents of different polarity and found out that the system phenoxathiin-thioxanthone presents a new emission band at longer wavelength than the D and A bands in non-polar solvents, which is quenched in polar ones. In order to explain the exciplex formation, which is determined by an electron transfer process, the standard free enthalpy for the latter was calculated according to the Rehm-Weller equation. The equilibrium constants and the activation barrier for the exciplex formation were determined as well from steadystate emission data at different donor concentrations and at different temperatures, respectively.

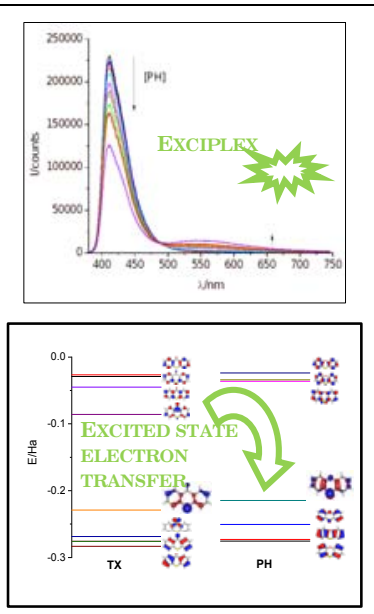

\section{INTRODUCTION}

Exciplexes are excited state complexes between an electron donor (D) and an electron acceptor (A) molecule stabilised in non-polar solvents, where the electron transfer becomes reversible. ${ }^{1}$ The literature data indicates that many times the $\mathrm{D}$ molecule contains a nitrogen atom ${ }^{25}$ or a methoxy group, ${ }^{6-8}$ among other cases. Exciplexes are intensely studied for their applications as OLED materials $^{9-14}$ and sensors. ${ }^{15}$ They are sometimes part of more complex photophysical processes. ${ }^{16,17}$
In this work we evidence the exciplex formation when the electron D contains sulphur as a D centre, i.e. an anthracene homologue, phenoxathiin ( $\mathrm{PH})$. Thioxanthone (TX) was used as an electron A. Its photophysical properties such as intensity and decay are solvent-dependent ${ }^{18-20}$ and it presents a relatively low singlet-triplet gap. ${ }^{21} \mathrm{TX}$ and its derivatives have been recently used as photoinitiators in polymerisation reactions ${ }^{22,23}$ and in light emitting devices based on thermally activated delayed fluorescence. ${ }^{24}$ New D-A pairs able to form emissive exciplexes may open up new directions in obtaining OLED devices with specific properties.

\footnotetext{
*Corresponding author: sorana@gw-chimie.math.unibuc.ro
} 
<smiles>O=c1c2ccccc2sc2ccccc12</smiles>

thioxanthone<smiles>c1ccc2c(c1)Oc1ccccc1S2</smiles>

phenoxathiin

Fig. 1 - Molecular structure of the electron A (thioxanthone) and D (phenoxathiin) molecules used.

\section{EXPERIMENTAL}

Thioxanthone and phenoxathiin were from Aldrich, spectroscopic grade. The solvents were from Aldrich, luminescence grade and were checked for fluorescence and used as received. Steady state fluorescence measurements were performed with an Edinburgh Instruments FLS920 spectrofluorimeter and the thermostated experiments on a JASCO 6300 spectrofluorimeter. The excitation wavelength was $380 \mathrm{~nm}$ for measuring emission spectra. Solutions of the order of $10^{-4} \mathrm{M}$ of TX were titrated with aliquots of $10^{-1} \mathrm{M} \mathrm{PH}$ in the respective solvent (final concentrations in the range 0$0.35 \mathrm{M}$ ). In order to determine the equilibrium constant for exciplex formation, emission data on the TX and exciplex bands were considered, for which the following equations were deduced and used in a global analysis procedure:

$$
\begin{gathered}
I_{A}=\frac{I_{A_{0}}}{1+K[D]} \\
I_{E}=\frac{I_{E_{0}}+I_{E_{\max }} K[D]}{1+K[D]}
\end{gathered}
$$

The temperature effect on exciplex formation was monitored measuring the emission spectrum of a mixture of $\mathrm{TX}$ and $\mathrm{PH}$ at different temperature and the apparent activation energy was determined from the equation:

$$
\ln \left(I_{E} / I_{A}\right)=\ln A-\frac{E_{a}}{R T},
$$

where the ratio is of the emission intensities on the exciplex and acceptor bands, respectively, and $\mathrm{A}$ is a preexponential factor.

Quantum chemical calculations were performed with Gaussian $09^{25}$ with the B3LYP functional ${ }^{26-28}$ and a 6$311++\mathrm{G}(2 \mathrm{~d}, 2 \mathrm{p})$ basis set, as it was found that lager basis sets do not further improve the electronic transition energies obtained in the frame of a specific computing method. ${ }^{29}$ Solvation was described with a continuum model, PCM ${ }^{30}$ and the solvents used were chloroform, dichloromethane and acetonitrile.

\section{RESULTS AND DISCUSSION}

The photophysical properties of TX have been already characterised and can be found in the literature ${ }^{18-20}$. Here nonprotic solvents of different polarities were used. TX presents a band at $412 \mathrm{~nm}$ in chloroform, 407 in dichloromethane and
$408 \mathrm{~nm}$ in acetonitrile, in agreement with literature data. Titration of TX with aliquots of $\mathrm{PH}$ solution results in a decrease of the emission intensity with increasing the concentration of the quencher in all the solvents used. Only in low polar solvents such as chloroform or dichloromethane a new wide band appears at $550 \mathrm{~nm}$, as can be seen in Figure 2. In acetonitril quenching occurs with no band appearing at longer wavelength with a Stern-Volmer constant of $5.64 \mathrm{M}^{-1}$.

TX and PH may function as electron acceptor and donor, respectively, in solution. To verify the possibility of a photoinduced electron transfer from PH to TX, the Gibbs free energy was calculated, according to the Rehm-Weller equation: ${ }^{31}$

$$
\Delta G^{0}=E\left(D / D^{+}\right)-E\left(A / A^{-}\right)-E_{00}-\frac{e^{2}}{4 \pi \varepsilon_{0} \varepsilon_{r} r_{D A}}
$$

where $\mathrm{E}\left(\mathrm{D} / \mathrm{D}^{+}\right)$is the oxidation potential of the donor, $\mathrm{E}\left(\mathrm{A} / \mathrm{A}^{-}\right)$ the reduction potential of the acceptor, $E_{00}$ the $S_{0} \rightarrow S_{1}$ energy gap of the fluorophore, $e$ the electron charge, $\varepsilon$ the solvent dielectric constant and $r_{D A}$ the donor-acceptor distance. All parameters are evaluated in acetonitrile. The oxidation potential of the donor and reduction potential of the acceptor vs. SCE were estimated from literature data, i.e. $\mathrm{E}\left(\mathrm{PH} / \mathrm{PH}^{+}\right)=1.25 \quad \mathrm{~V}^{32}, \quad \mathrm{E}\left(\mathrm{TX} / \mathrm{TX}^{-}\right)=-2.01 \mathrm{~V}^{33} \quad \mathrm{E}_{00} \quad$ was determined from the intersection of the absorption and fluorescence normalized spectra of TX as $3.17 \mathrm{eV}$, while the Coulombic term is approximated as $0.1 \mathrm{eV}$ in acetonitril according to literature. ${ }^{34}$ This yields a value of $\Delta G^{0}=-0.01$ $\mathrm{eV}$. Activated exciplex formation was found for donoracceptor systems with Gibbs free energies for the photoinduced electron transfer in the interval -0.1 $\mathrm{eV}<\Delta \mathrm{G}^{0}<0.1 \mathrm{eV}$. $^{35}$

The band at $550 \mathrm{~nm}$ that rises in intensity with rising $\mathrm{PH}$ concentration is assigned to an exciplex. The equilibrium constants for exciplex formation in chloroform and dichloromethane are presented in Table 1, while data fitting in chloroform may be viewed in Figure 2. It is highest in chloroform, $4.68 \mathrm{M}^{-1}$, of the same order of magnitude as the Stern-Volmer constant.

Emission spectra in chloroform and dichloromethane were measured at various temperatures. When temperature raises from 299 to $323 \mathrm{~K}$ the TX band decreases in intensity and the exciplex band increases, as seen in Figure 3. Temperture favours exciplex emission, either due to activated exciplex formation or to the temperature effect on the photophysical processes or both. The calculated activation energy is 4.6 $\mathrm{kcal} / \mathrm{mol}$ in chloroform and $2.7 \mathrm{kcal} / \mathrm{mol}$ in dichloromethane. One of the processes involved may be temperature activated delayed fluorescence of the exciplex and needs further investigation. 

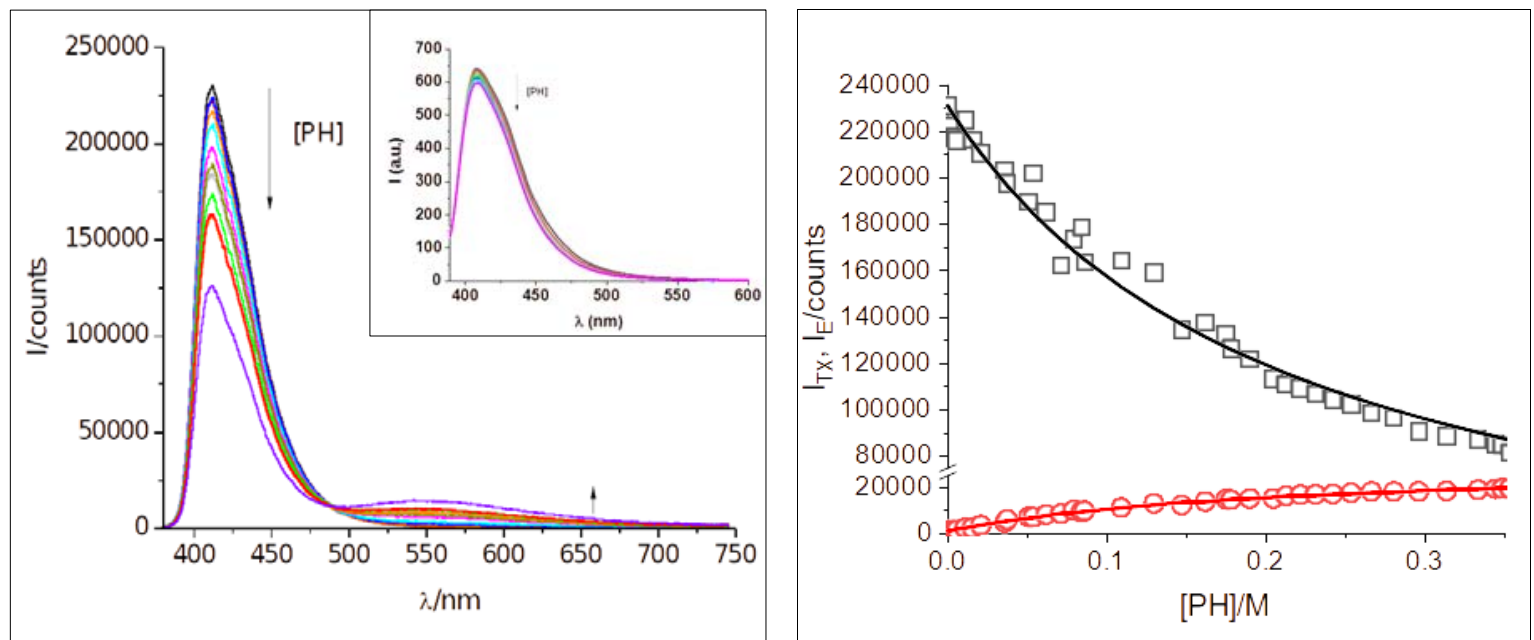

Fig. 2 - Left: Fluorescence spectra of TX in the presence of different concentrations of PH in chloroform. The arrow indicates increasing PH concentration. Inset: TX emission quenching by PH in acetonitrile. Right: data fitting on TX ( $\square$ ) and exciplex (०) bands in chloroform.

Table 1

Equilibrium constants and apparent activation energies for the studied exciplex. Coefficient of determination in parantheses

\begin{tabular}{c|c|c}
\hline Solvent & $\mathrm{K}\left(\mathrm{M}^{-1}\right)$ & $\mathrm{E}_{\mathrm{a}}(\mathrm{kcal} / \mathrm{mol})$ \\
\hline Chloroform & $4.68 \pm 0.11\left(\mathrm{R}^{2}=0.996\right)$ & $4.6 \pm 0.3\left(\mathrm{R}^{2}=0.976\right)$ \\
Dichloromethane & $3.33 \pm 0.07\left(\mathrm{R}^{2}=0.999\right)$ & $2.7 \pm 0.6\left(\mathrm{R}^{2}=0.957\right)$ \\
\hline
\end{tabular}
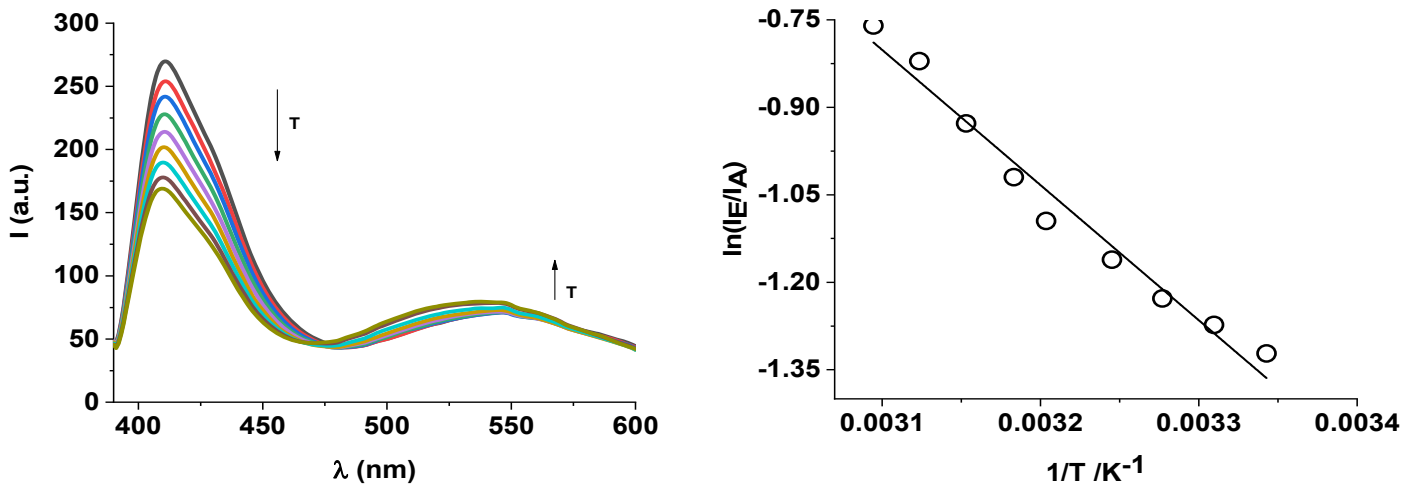

Fig. 3 - Temperature dependence of the emission spectrum of TX-PH D-A system in chloroform $(\mathrm{T}=299-323 \mathrm{~K})$ and plot of $\ln \left(\mathrm{I}_{\mathrm{E}} / \mathrm{I}_{\mathrm{A}}\right) v s .1 / \mathrm{T}$.
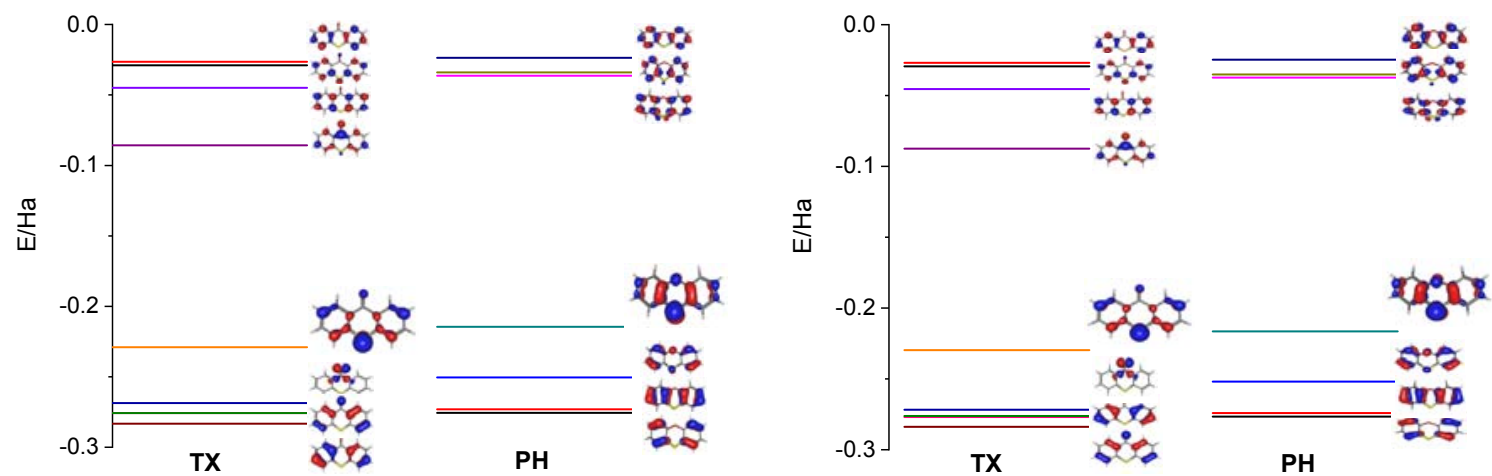

$\mathrm{PH}$

Fig. 4 - MO energies and shape in chloroform (left) and acetonitrile (right). The isodensity value is 0.05 e/Bohr ${ }^{3}$. 

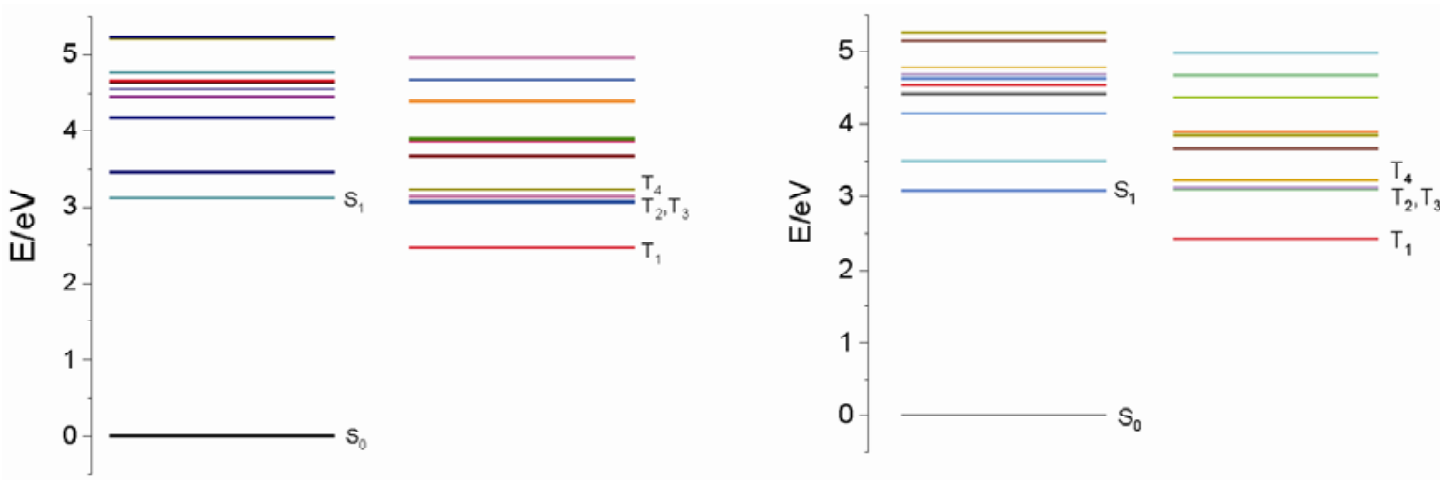

Fig. 5 - Singlet and triplet states for TX in chloroform (left) and acetonitrile (right).

The photoinduced electron transfer takes place if the energy of HOMO of D is higher than that of HOMO of A. This can be ascertained by quantum chemical calculations. The computed $\mathrm{MO}$ energies are presented in figure 4. Results in dichloromethane are very similar to the ones in chloroform and will not be presented. The electron transfer criterion is fulfilled in all solvents. In chloroform $\mathrm{E}_{\mathrm{HOMO}(\mathrm{PH})}=-5.84 \mathrm{eV}$, $\mathrm{E}_{\mathrm{HOMO}(\mathrm{TX})}=-6.23 \mathrm{eV}$, while in acetonitrile the values are -5.89 and $-6.25 \mathrm{eV}$, respectively. The changes in MO energy and electron density distribution are negligible from solvent to solvent in the frame of PCM solvation. Only quasi-degenerate MOs swaps on the energy scale take place, e.g. HOMO-2 and HOMO-3.

Solvation has little effect on the energy of the excited states, but enough to change the order of states in the singlet and triplet manifolds, as seen in figure 5. The first transition energy is $3.12 \mathrm{eV}$ in chloroform and $3.09 \mathrm{eV}$ in acetonitrile and corresponds to the HOMO-LUMO ${ }^{1}\left(\pi \pi^{*}\right)$ state. This is in very good agreement with the experimental values of $3.01 \mathrm{eV}$ in chloroform and $3.04 \mathrm{eV}$ in acetonitrile, with differences of around $0.1 \mathrm{eV}$. In chloroform two triplet states lay lower than the first excited singlet, from which $\mathrm{T}_{2},{ }^{3}\left(\mathrm{n} \pi^{*}\right)$, is located at $3.07 \mathrm{eV}$, so it is $0.05 \mathrm{eV}$ lower in energy. Another two are higher, but very closely located at 3.13 and $3.24 \mathrm{eV}$, both ${ }^{3}\left(\pi \pi^{*}\right)$, yielding a difference of as little as $0.01 \mathrm{eV}$ or $80 \mathrm{~cm}^{-1}$. In acetonitrile the ${ }^{3}\left(\mathrm{n} \pi^{*}\right)$ becomes higher in energy, with 3.11 $\mathrm{eV}$, but very close to ${ }^{1}\left(\pi \pi^{*}\right)$ at $3.09 \mathrm{eV}$. Other triplets are also close, at 3.13 and $3.23 \mathrm{eV}$, both ${ }^{3}\left(\mathrm{n} \pi^{*}\right)$ in nature. Small S-T gaps are mandatory for the back ISC process to take place, giving rise to thermally activated delayed fluorescence. IC processes between close lying triplet states are also important in this process and $\mathrm{T}_{2}$ to $\mathrm{T}_{4}$ are within $0.1 \mathrm{eV}$ of one another for TX in all solvents.

\section{CONCLUSIONS}

Exciplexes in bimolecular systems with an electron donor that contains sulphur, phenoxathiin, and thioxanthone as acceptor were obtained and their equilibrium constants and temperature dependence determined. Quantum chemical calculations predict that the photoinduced electron transfer is spontaneous in solvents of different polarities. This new class of electron donors is under further investigation in view of understanding the complex photophysical processes taking place and finding optimal donoracceptor pairs for application in OLED devices.

\section{REFERENCES}

1. B. Valeur, "Molecular Fluorescence Principles and Applications", WILEY-VCH Verlag, Weinheim, Germany, 2002.

2. G. Xie, Y. Sueishi and S. Yamamoto, J. Fluoresc., 2005, 15,475483 .

3. N. Mataga, H. Chosrowjan and S. Taniguchi, J. Photochem. Photobiol. C: Photochem. Rev., 2005, 6, 37-79.

4. N. Mataga, Pure \& Appl. Chem., 1997, 69, 729734.

5. C. D. Borsarelli, S. G. Bertolotti and C. M. Previtali, Photochem. Photobiol., 2001, 73, 97104.

6. M. G. Kuzmin, I. V. Soboleva, E. V. Dolotova and D. N. Dogadkin, Photochem. Photobiol. Sci., 2003, 2, 967-974.

7. D. N. Dogadkin, E. V. Dolotova, I. V. Soboleva, M. G. Kuzmin, V. F. Plyusnin, I. P. Pozdnyakov and V. P. Grivin, High Energ. Chem., 2005, 39, 20-25.

8. M. Dossot, X. Allonas and P. Jacques, Chem. Eur. J., 2005, 11, 1763 - 1770 .

9. D. Chen, Z. Wang, D. Wang, Y. C. Wu, C. C. Lo, A. Lien, Y. Cao and S. J. Su, Org. Electron., 2015, 25, 79-84.

10. J. Zhao, X. Du, S. Yuan, C. Zheng, H. Lin and S. Tao, Org. Electron., 2017, 43, 136141.

11. E. Skuodis, A. Tomkeviciene, R. Reghu, L. Peciulyte, K. Ivaniuk, D. Volyniuk, O. Bezvikonnyi, G. Bagdziunas, D. Gudeika and J. V. Grazulevicius, Dyes Pigm., 2017, 139, 795807

12. M. Bezugly, K. Ivaniuk, D. Volyniuk, J. V. Gražulevičius and G. Bagdžiūnas, Dyes Pigm., 2018, 149, 298-305.

13. G. Grybauskaite-Kaminskiene, K. Ivaniuk, G. Bagdziunas, P. Turyk, P. Stakhira, G. Baryshnikov, D. Volyniuk, V. Cherpak, B. Minaev, Z. Hotra, H. Ågren and J. V. Grazulevicius, J. Mater. Chem. C, 2018, 6, 15431550.

14. Q. Wang, Q. S. Tian, Y. L. Zhang, X. Tang and L. S. Liao, J. Mater. Chem. C, 2019, 7, 1132911360.

15. J. Hirota, K. Usui, Y. Fuchi, M. Sakuma, S. Matsumoto, R. Hagihara and S. Karasawa, Chem. Eur. J., 2019, 25, 14943 - 14952.

16. T. M. Safko, M. M. Faleiros, T. D. Z. Atvars and R. G. Weiss, J. Phys. Chem. A, 2016, 120, 3983-3991.

17. M. J. Bertocchi, X. F. Zhang, A. Bajpai, J. N. Moorthy and R. G. Weiss, J. Photochem. Photobiol. A: Chem., 2018, 355, 467-478.

18. J. Christopher Dalton and F. C. Montgomery, J. Am. Chem. Soc., 1974, 96, 62306232. 
19. D. Burget and P. Jacques, J. Lumin., 1992, 54, 177-181.

20. E. Krystkowiak, A. Maciejewski and J. Kubicki, ChemPhysChem, 2006, 7, 597606.

21. H. Wang, H. Xie, Q. Peng, L. Meng, Y. Wang, Y. Yi and P. Wang, Adv. Mat., 2014, 26, 5198-5204.

22. S. K. Dogruyol, Z. Dogruyol and N. Arsu, J. Polym. Sci. A: Polym. Chem., 2011, 49, 40374043.

23. D. K. Balta and N. Arsu, Design. Monom. Polym., 2016, 19, 222-226.

24. Z. Wang, Y. Li, X. Cai, D. Chen, G. Xie, K. Liu, Y. C. Wu, C. C. Lo, A. Lien, Y. Cao and S. J. Su, ACS Appl. Mater. Interfaces, 2016, 8, 8627-8636.

25. Gaussian 09, Revision C.01, M. J. Frisch, G. W. Trucks, H. B. Schlegel, G. E. Scuseria, M. A. Robb, J. R. Cheeseman, G. Scalmani, V. Barone, B. Mennucci, G. A. Petersson, H. Nakatsuji, M. Caricato, X. Li, H. P. Hratchian, A. F. Izmaylov, J. Bloino, G. Zheng, J. L. Sonnenberg, M. Hada, M. Ehara, K. Toyota, R. Fukuda, J. Hasegawa, M. Ishida, T. Nakajima, Y. Honda, O. Kitao, H. Nakai, T. Vreven, J. A. Montgomery, Jr., J. E. Peralta, F. Ogliaro, M. Bearpark, J. J. Heyd, E. Brothers, K. N. Kudin, V. N. Staroverov, R. Kobayashi, J. Normand, K. Raghavachari, A. Rendell, J. C. Burant, S. S. Iyengar, J. Tomasi, M. Cossi, N. Rega, J. M. Millam, M. Klene, J. E. Knox, J. B. Cross, V. Bakken, C. Adamo, J. Jaramillo, R. Gomperts, R. E. Stratmann, O. Yazyev, A. J. Austin, R. Cammi, C. Pomelli, J. W.
Ochterski, R. L. Martin, K. Morokuma, V. G. Zakrzewski, G. A. Voth, P. Salvador, J. J. Dannenberg, S. Dapprich, A. D. Daniels, Ö. Farkas, J. B. Foresman, J. V. Ortiz, J. Cioslowski and D. J. Fox, Gaussian, Inc., Wallingford CT, 2009.

26. A. D. Becke, J. Chem. Phys., 1993, 98, 56485652.

27. C. Lee, W. Yang and R. G. Parr, Phys. Rev. B, 1988, 37, 785789.

28. P. J. Stephens, F. J. Devlin, C. F. Chabalowski, M. J. Frisch, J. Phys. Chem., 1994, 98, 1162311627.

29. A. D. Becke, J. Chem. Phys., 1993, 98, 56485652; C. Lee, W. Yang and R. G. Parr, Phys. Rev. B, 1988, 37, 785789; P. J. Stephens, F. J. Devlin, C. F. Chabalowski, M. J. Frisch, J.Phys.Chem., 1994, 98, 1162311627.

30. J. Tomasi, B. Mennucci and R. Cammi, Chem. Rev., 2005, 105, 29993093.

31. D. Rehm and A. Weller, Isr. J. Chem., 1970, 8, 259262.

32. S. M. Park and A. J. Bard, Chem. Phys. Lett., 1976, 38, 257262.

33. E. W. Tsai, L. Throckmorton, R. Mckellar, M. Baar, M. Kluba, D. S. Marynick, K. Rajeshwar and A. L. Ternay, Jr., J. Electroanal. Chem., 1986, 210, 4567.

34. G. Jones, S. F. Griffin, C. Choi and W. R. Bergmark, J.Org. Chem., 1984, 49, 27052708.

35. M. G. Kuzmin, I. V. Soboleva, E. V. Dolotova and D. N. Dogadkin, Photochem. Photobiol. Sci., 2003, 2, 967-974. 
